\title{
ОЦЕНКА АДАПТИВНЫХ СПОСОБНОСТЕЙ БИЗНЕС-МОДЕЛЕЙ РОССИЙСКИХ КОММЕРЧЕСКИХ БАНКОВ
}

\author{
(c) 2019 Зинина Мария Михайловна \\ аспирантка Департамента финансовых рынков и банков \\ Финансовый университет при Правительстве Российской Федерации, Россия, Москва \\ Email: nat-zinina@yandex.ru
}

В статье проводится оценка способностей бизнес-моделей коммерческих банков адаптироваться к условиям макроэкономической среды, что особенно актуально при волатильной конъюнктуре. Автор предлагает использовать метод стресс-тестирования, который позволяет определить устойчивость различных банковских бизнес-моделей к внешним шокам. В ходе исследования выявлены наиболее и наименее устойчивые типы бизнес-моделей российских кредитных организаций.

Ключевые слова: бизнес-модель, коммерческий банк, стресс-тестирование, адаптивность, финансовая устойчивость, универсальный банк, иностранная дочерняя структура, банк «монолайнер», банк «кредитный агрессор», банк «без бизнеса».

В данном исследовании предлагается проверить гипотезу о том, что современные бизнесмодели российских кредитных организаций разделяются на следующие типы, имеющие различные способности адаптации к условиям внешней среды: универсальный банк федерального и регионального масштабов, иностранная дочерняя структура, монолайнер, кредитный агрессор и банк «без бизнеса». Наиболее адекватным инструментом, позволяющим оценить адаптивные способности бизнес-моделей коммерческих банков, выражающиеся в приспособлении к изменяющимся условиям макроэкономической среды при сохранении финансовой устойчивости, выступает стресс-тестирование. На основе стресс-теста представляется возможным определить объем потерь для бизнесмоделей кредитных организаций по направлениям их деятельности в целях выявления наиболее уязвимых областей для каждого типа банковской бизнес-модели [2].

В рамках стресс-тестирования, проводимого автором на основе отчетности МСФО за 2017 год с использованием базы данных Orbis Bank Focus, целесообразно оценить влияние ухудшения макроэкономических факторов на показатели достаточности и рентабельности капитала для различных типов банковских бизнес-моделей на основе следующих допущений:

- показатели ликвидности не рассматриваются в качестве результирующих факторов модели стресс-теста ввиду профицита ликвидных активов в российском банковском секторе, на-

блюдавшегося в 2017 году;

- для перевода данных, представленных в базе Orbis Bank Focus, из долларов США в рубли используется официальный курс ЦБ РФ, установленный на 31.12.2017 (57,6 рублей за 1 доллар США);

- значения макроэкономических стрессфакторов определяются исходя из наихудших значений, наблюдаемых в прошлом, т.е. методом исторического моделирования;

- не подвергаются стресс-тесту наиболее ликвидные активы (денежные средства, МБК, остатки на НОСТРО-счетах), основные средства и прочие активы ввиду их низкой подверженности влиянию макроэкономических параметров, а также портфель ценных бумаг до погашения ввиду отсутствия переоценки по ним на балансе и, как следствие, влияния на капитал и финансовый результат;

- в целях упрощения стресс-тестирования норматива Н1.0 примем величину активов, взвешенных по степени риска (RWA), за константу;

- при оценке изменения резервов по кредитам ЮЛ и ФЛ примем за константу по каждому типу бизнес-модели отношение коэффициента резервирования к уровню просроченной задолженности (данные по просроченной задолженности ЮЛ и ФЛ для всех бизнес-моделей будут соответствовать их значению в целом по банковскому рынку);

- ввиду отсутствия данных по резервам в разрезе кредитов ЮЛ и ФЛ будет использоваться статистика по совокупному объему резервов, 
характерного для каждой бизнес-модели, а изменение величины резервов по кредитам ЮЛ и ФЛ будет рассчитываться как произведение совокупного объема резервов на долю кредитов ЮЛ и ФЛ в ссудном портфеле соответствующей бизнес-модели.

На основе принятых выше допущений проведем переоценку торгового портфеля ценных бумаг и ссудного портфеля ЮЛ и ФЛ, оказывающих существенное влияние на величину собственных средств и финансового результата кредитных организаций.

В качестве индикатора оценки стоимости торгового портфеля ценных бумаг будем использовать композитный индекс облигаций Московской Биржи (RUABITR), что обусловлено преобладанием облигаций и незначительной долей акций на российском фондовом рынке. Индекс RUABITR является наиболее содержательным показателем (включает в себя ОФЗ, субфедеральные и муниципальные ценные бумаги, облигации публичных российских корпоративных эмитентов) и позволяет оценить динамику и доходность всего фондового рынка России. Для определения критической величины композитного индекса облигаций Московской Биржи произведем выгрузку его котировок с 01.12.2010 по 31.12.2017, рассчитаем ежемесячную динамику индекса и найдем наименьшее значение. Tак, максимальное падение индекса RUABITR достигло 11 п.п. в декабре 2014 года [5], что было обусловлено существенным ростом ключевой ставки и девальвацией рубля. Далее для каждого типа бизнес-модели необходимо определить величину отрицательной переоценки торгового портфеля ценных бумаг как произведение портфеля ценных бумаг на минимальное значение динамики индекса RUABITR (-11 п.п.).

При проведении стресс-тестирования ссудных портфелей ЮЛ и ФЛ в качестве риск-факторов будем использовать динамику просроченной задолженности и уровня резервирования. Для определения параметров стресс-теста кредитных портфелей предлагается построить уравнения множественной регрессии через приращения объясняющих переменных за период с 2006 по 2017 гг., описывающие влияние макроэкономических факторов на динамику доли просроченной задолженности в разрезе кредитов ЮЛ и ФЛ [4]. Затем необходимо проверить наличие статистической связи между объясняющими и объясняемыми переменными с помощью составления корреляционной матрицы по динамике просроченной задолженности ЮЛ и ФЛ и различных макроэкономических факторов. В результате определения наиболее значимых параметров и их весов уравнение регрессии по динамике просроченной задолженности ЮЛ имеет следующий вид:

$\Delta \Pi$ ПЮЛ $)=-0,0046 * \mathrm{a}_{2}+0,0581 * \mathrm{a}_{6}-0,3672 *$ $\mathrm{a}_{7}+0,413 * \mathrm{a}_{18}$,

где $\mathrm{a}_{2}$ - темпы экономического роста, $\mathrm{a}_{6}-$ динамика ключевой ставки, $\mathrm{a}_{7}$ - динамика индекса производительности труда, $\mathrm{a}_{18}$ - динамика доли просроченной задолженности ЮЛ.

Регрессионное уравнение, описывающее динамику просроченной задолженности ФЛ, выглядит следующим образом:

$\Delta \Pi З(Ф Л)=0,2743 * \mathrm{~b}_{2}+0,0443 * \mathrm{~b}_{4}-0,2412 *$ $\mathrm{b}_{5}-0,0197 * \mathrm{~b}_{8}$,

где $\mathrm{b}_{2}$ - динамика индекса потребительских цен, $\mathrm{b}_{4}$ - ключевая ставка ЦБ РФ, $\mathrm{b}_{5}$ - темпы экономического роста, $\mathrm{b}_{8}$ - динамика реальных располагаемых денежных доходов населения.

Далее найдем критические значения прироста просроченной задолженности ЮЛ и ФЛ, определив наихудшие величины рассматриваемых макроэкономических факторов за период 2006-2017 гг. и подставив их в регрессионные уравнения. Проведенные расчеты показали, что просроченная задолженность ЮЛ и ФЛ в шоковых условиях внешней среды может вырасти на 5,5 и 6,1 п.п. соответственно. Указанные параметры будем использовать для определения потенциального досоздания резервов в соответствии с принятыми ранее допущениями. В частности, определим соотношение коэффициента резервирования и уровня просроченной задолженности в разрезе кредитов ЮЛ и ФЛ и, принимая его за константу, оценим изменение коэффициента резервирования при росте уровня просроченной задолженности ЮЛ и ФЛ в стрессовом сценарии по различным типам банковских бизнесмоделей.

Обобщив проведенные расчеты по отрицательной переоценке торгового портфеля ценных бумаг и доформированию резервов при ухудшении параметров макросреды, проведем оценку их влияния на H1.0 и ROE в соответствии с предположением о том, что величина активов под риском является константой (см. таблицу 1).

Опираясь на результаты проведенного стресс-теста, можно отметить, что банки с универсальной бизнес-моделью федерального 
Таблица 1. Результаты стресс-тестирования бизнес-моделей российских коммерческих банков на 01.01.2018

\begin{tabular}{|c|c|c|c|c|c|c|c|c|c|c|c|c|}
\hline \multirow{2}{*}{$\begin{array}{l}\text { Тип бизнес-модели } \\
\text { / Риск-факторы }\end{array}$} & \multicolumn{2}{|c|}{$\begin{array}{l}\text { Универсаль- } \\
\text { ный (феде- } \\
\text { рального } \\
\text { масштаба) }\end{array}$} & \multicolumn{2}{|c|}{$\begin{array}{c}\text { Универсаль- } \\
\text { ный (реги } \\
\text { онального } \\
\text { масштаба) }\end{array}$} & \multicolumn{2}{|c|}{$\begin{array}{l}\text { Иностранная } \\
\text { дочерняя } \\
\text { структура }\end{array}$} & \multicolumn{2}{|c|}{ Монолайнер } & \multicolumn{2}{|c|}{$\begin{array}{l}\text { Кредитный } \\
\text { агрессор }\end{array}$} & \multicolumn{2}{|c|}{ Без бизнеса } \\
\hline & $\underset{\tilde{U}}{\tilde{\theta}}$ & 总 & $\underset{\tilde{\theta}}{\bar{\theta}}$ & 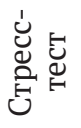 & 咅 & 己⿱丷己心 & $\underset{\tilde{\theta}}{\tilde{\theta}}$ & 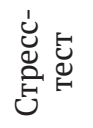 & 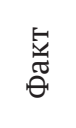 & 己ֶّ & $\frac{E}{\tilde{\theta}}$ & 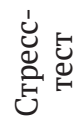 \\
\hline $\begin{array}{l}\text { Совокупная вели- } \\
\text { чина переоценки } \\
\text { ценных бумаг по } \\
\text { стрессовому сце- } \\
\text { нарию, млрд. руб. }\end{array}$ & \multicolumn{2}{|c|}{-466} & \multicolumn{2}{|c|}{-29} & \multicolumn{2}{|c|}{-33} & \multicolumn{2}{|c|}{-30} & \multicolumn{2}{|c|}{-9} & \multicolumn{2}{|c|}{-12} \\
\hline $\begin{array}{l}\text { Объем РВПС по } \\
\text { ссудам ЮЛ и ФЛ } \\
\text { к досозданию по } \\
\text { стрессовому сце- } \\
\text { нарию, млрд. руб. }\end{array}$ & \multicolumn{2}{|c|}{164} & \multicolumn{2}{|c|}{10} & \multicolumn{2}{|c|}{5} & \multicolumn{2}{|c|}{35} & \multicolumn{2}{|c|}{14} & \multicolumn{2}{|c|}{13} \\
\hline $\begin{array}{l}\text { Фактическая } \\
\text { величина активов } \\
\text { под риском (RWA), } \\
\text { млрд. руб. }\end{array}$ & \multicolumn{2}{|c|}{61370} & \multicolumn{2}{|c|}{1786} & \multicolumn{2}{|c|}{4204} & \multicolumn{2}{|c|}{2286} & \multicolumn{2}{|c|}{1083} & \multicolumn{2}{|c|}{630} \\
\hline Капитал, млрд. руб. & 6597 & 5967 & 242 & 202 & 724 & 687 & 262 & 197 & 109 & 86 & 138 & 114 \\
\hline $\begin{array}{l}\text { Финансовый ре-- } \\
\text { зультат, мл руб. }\end{array}$ & 989 & 359 & 29 & -11 & 96 & 58 & 27 & -38 & -8 & -32 & -5 & -29 \\
\hline $\mathrm{H} 1.0$ & $11 \%$ & $10 \%$ & $14 \%$ & $11 \%$ & $17 \%$ & $16 \%$ & $12 \%$ & $9 \%$ & $10 \%$ & $8 \%$ & $22 \%$ & $18 \%$ \\
\hline ROE & $15 \%$ & $6 \%$ & $12 \%$ & $-5 \%$ & $13 \%$ & $8 \%$ & $10 \%$ & $-19 \%$ & $-8 \%$ & $-37 \%$ & $-4 \%$ & $-26 \%$ \\
\hline
\end{tabular}

Источник: составлено автором на основе данных Orbis Bank Focus [3]

масштаба характеризуются приемлемой финансовой устойчивостью к внешним шокам. Так, рентабельность их капитала несмотря на небольшое падение (-9 п.п.) сохраняет положительное значение на уровне 6\%. Норматив Н1.0 изначально имел слабый запас $(10,8 \%)$, а в условиях ухудшения параметров макроэкономической среды его значение опустилось до 9,7\%. Стоит отметить, что для банков данной группы действуют дополнительные надбавки (включая надбавку за системную значимость), с учетом которых значение достаточности собственных средств на 1 января 2018 г. должно составлять не менее $10,525 \%$. Однако особый статус кредитных организаций с данной бизнес-моделью повышает вероятность введения послаблений со стороны Банка России в части минимально допустимой величины Н1.0 в целях поддержания стабильного состояния банковского сектора и экономики в целом.

Для банков с универсальной бизнес-моделью регионального масштаба по итогам стресстестирования свойственна средняя финансовая устойчивость, что обусловлено, с одной стороны, сохранением достаточности собственных средств на приемлемом уровне (H1.0 $=11 \%$ в условиях стресса), а, с другой стороны, существенным снижением рентабельности (с $12 \%$ до $-5 \%)$. Падение ROE по кредитным организациям данной бизнес-модели в основном связано с возникновением единоразовой отрицательной переоценки по ценным бумагам, при этом досоздание РВПС оказалось не столь существенным по сравнению с другими типами бизнесмоделей.

В свою очередь, наибольшую устойчивость к внешним шокам показали иностранные дочерние структуры. Показатели достаточности собственных средств и рентабельности капитала по данному типу бизнес-модели характеризуются наименьшей отрицательной динамикой и, даже несмотря на снижение, продолжают сохранять высокие значения: Н1.0 сократился с 17 до 16\%, ROE - с 13\% до 8\%. Подобный результат демонстрирует адекватные способности бизнес-модели иностранных дочерних структур адаптироваться к изменяющимся условиям макросреды, что обусловлено в т.ч. высокой эффективностью корпоративного управления и риск-менеджмента, выстроенных на уровне ма- 
теринских банковских групп.

Банки с бизнес-моделью монолайнера показали наименьшую устойчивость в условиях стресса. Важно отметить, что по данной группе банков значения достаточности собственных средств и рентабельности до кризиса находились на приемлемом уровне (H1.0=12\%, ROE=10\%). Однако при реализации кризисного сценария значения рассматриваемых показателей опустились до крайне низких уровней (H1.0=9\%, ROE= $-19 \%)$, на основе чего можно сделать вывод об отсутствии адаптивных способностей и высокой рискованности бизнеса банков-монолайнеров.

Для бизнес-модели «кредитный агрессор» еще до проведения стресс-теста была характерна слабая финансовая устойчивость, обусловленная низким значением норматива достаточности собственных средств (H1.0 $=10 \%)$ и убыточностью деятельности (ROE $=-8 \%)$. В свою очередь, ухудшение параметров макроэкономической среды привело к усугублению финансового положения банков данного типа бизнес-модели: H1.0 опустился до $8 \%$, ROE - до $-37 \%$, что является наихудшим результатом по сравнению с другими бизнес-моделями.

Банки «без бизнеса» отличаются существенной долей безрисковых активов и, как следствие, высоким запасом по капиталу (H1.0 $=22 \%)$, что позволяет им выдержать стресс-тест при сохранении норматива Н1.0 на высоком уровне $(\mathrm{H} 1.0=18 \%)$. С другой стороны, принятие пониженного риска в результате значительного объема денежных средств, ценных бумаг, МБК на балансе сопряжено с слабыми показателями рентабельности деятельности по данному типу бизнес-модели. Так, ROE составляла $-4 \%$ еще до проведения стресс-тестирования, а при реализации стрессового сценария значение показателя снизилось до -25\%. Указанные результаты характеризуют способность банков «без бизнеса» $\mathrm{K}$ генерации прибыли как крайне слабую, что обусловлено невысоким уровнем корпоративного управления при неэффективном размещении привлеченных и собственных средств и свидетельствует о низких адаптивных способностях данного типа бизнес-модели.

Таким образом, проведенный стресс-тест подтверждает выдвинутую автором гипотезу и позволяет определить, что наилучшими адаптивными способностями обладают банки с универсальной бизнес-моделью федерального масштаба и зарубежные дочерние структуры, среднюю способность адаптироваться к внешним шокам продемонстрировали универсальные банки регионального масштаба, низким уровнем адаптации обладают банкимонолайнеры, кредитные агрессоры и банки «без бизнеса» [1]. То есть сокращение объемов бизнеса и значимости банка для банковского рынка коррелирует с ростом подверженности бизнес-модели кредитной организации к реализации различных рисков и уменьшением способности бизнес-модели адаптироваться к условиям внешней среды.

\section{Библиографический список}

1. Зинина М.М. Сущность процесса адаптации бизнес-моделей кредитных организаций под влиянием макроэкономической среды // Финансовая экономика, № 1, 2019, с. 737-739.

2. Мешкова Е.И. Стресс-тестирование в коммерческом банке.- М: Регламент-Медиа, 2014.

3. Официальный сайт базы данных Orbis Bank Focus компании Bureau van Dijk Electronic Publishing (BvDEP) [Электронный ресурс].- Режим доступа: https://banks.bvdinfo.com/version-2019118/home. serv?product=OrbisBanks

4. Официальный сайт Банка России [Электронный ресурс]. - Режим доступа: https://www.cbr.ru/

5. Официальный сайт ПАО Московская биржа [Электронный ресурс].- Режим доступа: https://www.moex. com/ru/index/RUABITR 